\title{
High Voltage of two Batteries - two five-levels NPC voltages sources inverters Cascade. Application to the DSIM Drive
}

\author{
S. Arezki ${ }^{1}$, E.M. Berkouk ${ }^{2}$ \\ ${ }^{1}$ Université des Sciences \\ et de la Technologie Houari Boumediene, \\ B.p.32, El-Alia, 16111 Bab-Ezzouar, Alger. \\ E-mail : arezki_saliha@yahoo.fr \\ ${ }^{2}$ Laboratoire de commande des processus. Ecole Nationale Polytechnique d'Alger-10, rue Hassen Badi, El Harrach, \\ Alger BP182 ALGERIA. Email:emberkouk@Yahoo.fr
}

\begin{abstract}
In this paper, the authors present the stability problem of the input DC voltages of the five levels neutral point clamping (NPC), when power is provided by a continuous source constant (Batterie).

In order to sabilisis these DC voltages, they present and study a new cascade: two batteries-two capacitors filterstwo five levels NPC voltage source inverter (VSI) applies to the double star induction machine (DSIM).

The results show that the input DC voltages of the two inverters are not stable. To improve the performances of the cascade and to stabilise the input DC voltages, the authors propose in this paper a solution that uses a clamping bridge. The result confirms the good performances of the proposed solution. So it is full of promise to use this inverter in high voltage and great power applications.
\end{abstract}

\section{Key words}

Stability, Input DC Voltages, space vector modulation Strategy, Multilevel NPC, Clamping bridge, DSIM.

\section{Introduction}

The unbalance of the different DC voltages sources of the five levels NPC VSI constituted the major limitation for the uses of this new power converter [1]. In order to stabilise these DC voltages, they propose to study a new cascade. Preliminary, they remained the knowledge model of the multilevel inverter, and its control strategy. Next, they study the control speed of the DSIM using rotor field oriented. Then, they present the model to the filter intermediate. After that, the authors study the stability problem of the input DC voltages of the inverter. Thus, they study a cascade constituted by two batteries- two capacitors filters-two five levels NPC VSI. The results obtained show that the input DC voltages of the two inverters are not stable. To improve the performances of the proposed cascade and stabilise the input DC voltages, the authors propose in this paper one solution, which uses a clamping bridge [1]. The results obtained are full of promise to use this inverter in high voltage and great power applications.

\section{Modelling of five levels NPC voltage source inverter}

\section{A. The three phases five-levels NPC VSI structure}

The five levels NPC VSI is constituted by three arms and five DC voltages sources. Every arm has eight bidirectional switches, six in series and two in parallel, and two diodes. Every switch is composed by a transistor and a diode in anti- parallel.

The (fig. 1) presents the structure of this inverter [2]

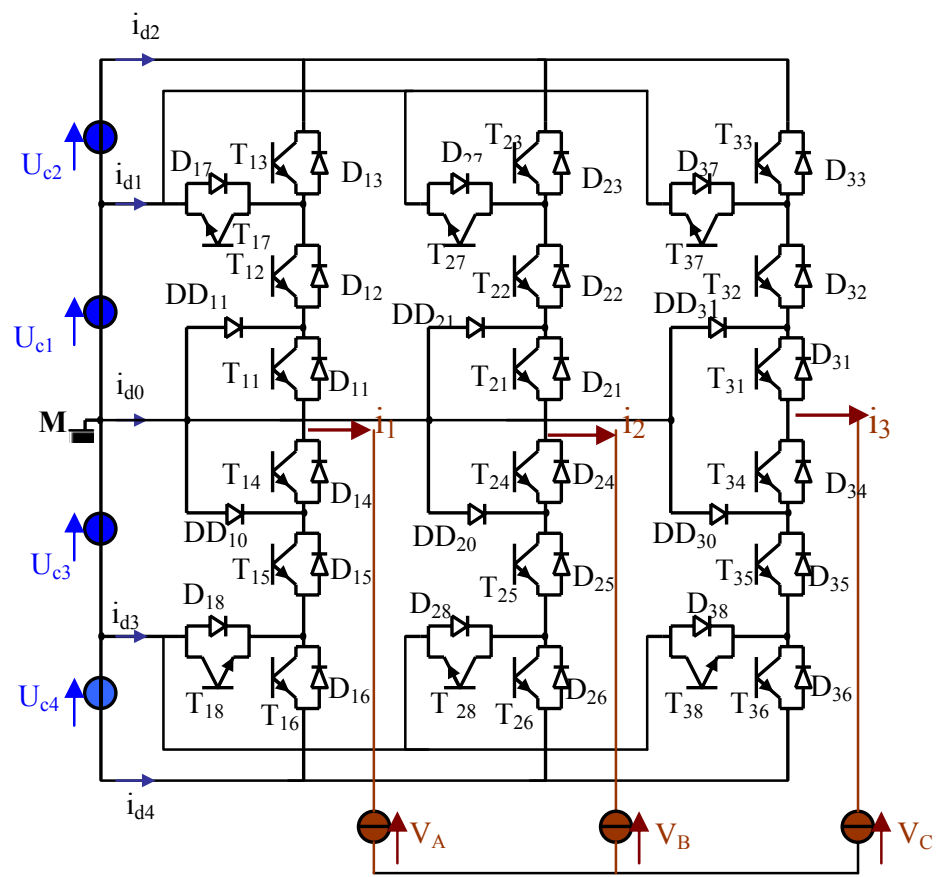

Fig. 1. A five levels NPC voltage source inverter 


\section{B. Knowledge model of the five levels NPC VSI}

The knowledge model of this converter is developed using switch connection function $\mathrm{F}_{\mathrm{ks}}(\mathrm{k}$ : number of arm and $\mathrm{s}:$ number of the semi-conductor).

The voltages of the three phases A, B and C, relatively to the middle point $\mathrm{M}$, are given by the following system:

$$
\left[\begin{array}{l}
V_{A M} \\
V_{B M} \\
V_{C M}
\end{array}\right]=\left[\begin{array}{l}
F_{17}+F_{11}^{b} \\
F_{27}+F_{21}^{b} \\
F_{37}+F_{31}^{b}
\end{array}\right] U_{C 1}+\left[\begin{array}{l}
F_{11}^{b} \\
F_{21}^{b} \\
F_{31}^{b}
\end{array}\right] U_{C 2}-\left[\begin{array}{l}
F_{18}+F_{10}^{b} \\
F_{28}+F_{20}^{b} \\
F_{38}+F_{30}^{b}
\end{array}\right] U_{C 3}-\left[\begin{array}{l}
F_{10}^{b} \\
F_{20}^{b} \\
F_{30}^{b}
\end{array}\right] U_{C 4}
$$

The system (1) shows that a five levels NPC voltage source inverter can be considered as four two levels voltage source inverter or two three levels voltage source inverter.

\section{Space vector modulation strategy}

The strategy proposed in this paper used four bipolar carriers. It is characterised by two parameters: modulation index $\mathrm{m}$ and modulation rate $\mathrm{r}$ [4].

The (fig. 2) shows the signal of this strategy.

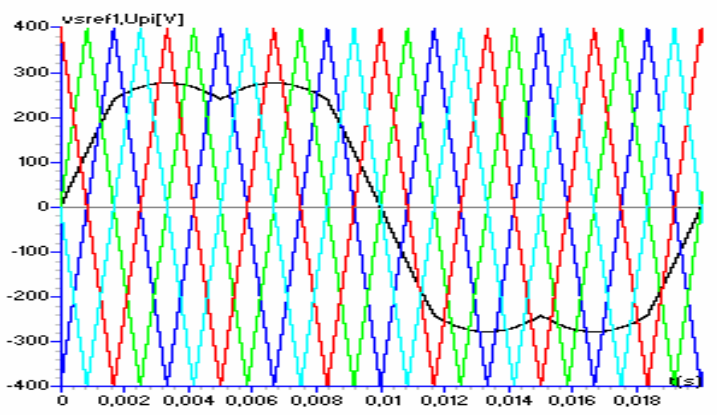

Fig. 2. Space vector modulation with four carriers bipolars $(\mathrm{m}=6, \mathrm{r}=0.8)$

The principal of this strategy consists to defines from vector reference $V_{\text {sref }}, V_{\text {sref }}=\left(V_{\text {ref1 }}, V_{\text {ref2 }}, V_{\text {ref3 }}\right)^{t}$, a new reference vector $V_{\text {srefl }}$ whose the composants are defined by the following equation system

$\mathrm{V}_{\text {srefl } 1}[\mathrm{i}]=\mathrm{V}_{\text {sref }}[\mathrm{i}]+\mathrm{V}_{\mathrm{o}}$, with; $\mathrm{V}_{\mathrm{o}}=\frac{\left[\max \left(\mathrm{V}_{\text {sref }}\right)+\min \left(\mathrm{V}_{\text {sref }}\right)\right]}{2}$.

\section{Double star induction machine drive}

\section{A. Double star induction machine (DSIM) modelling}

The studied machine is a double star induction motor. It is constituted by two three phase windings in the stator shifted between then with an angle of $30^{\circ}$ and one three phase windings in the rotor (fig. 3)[2,3].

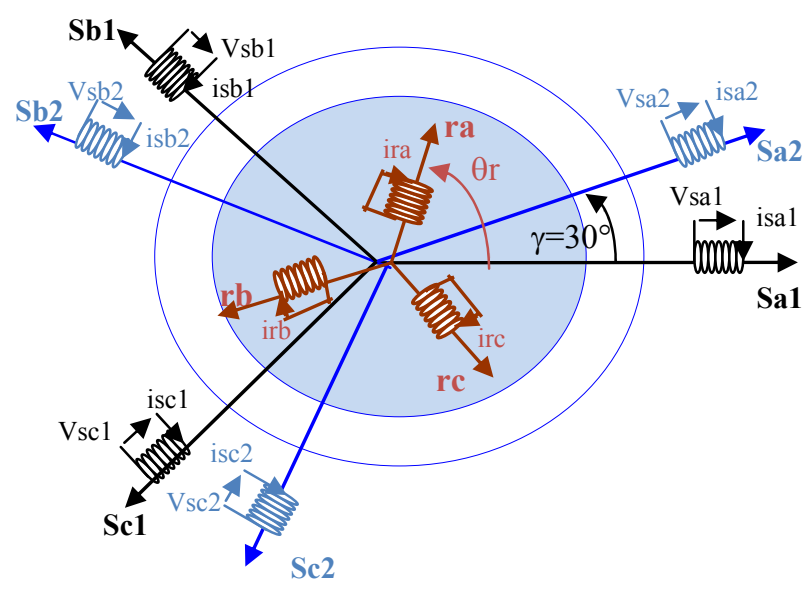

Fig. 3. Magnetising axes of the $2 * 3$ phase

The PARK model of the DSIM, with p pairs of poles, is defined by the following equation system $(2)[2,4]$.

$$
\left\{\begin{array}{l}
V_{s d 1}=r_{s 1 .} i_{s d 1}+\frac{d p h_{s d 1}}{d t}-\omega s \cdot p h_{s q 1} \\
V_{s q 1}=r_{s 1 . i_{s q 1}}+\frac{d p h_{s q 1}}{d t}+\omega s \cdot p h_{s d 1} \\
V_{s d 2}=r_{s 2 . i_{s d} 2}+\frac{d p h_{s d 2}}{d t}-\omega s \cdot p h_{s q 2} \\
V_{s q 2}=r_{s 2} \cdot i_{s q 2}+\frac{d p h_{s q 2}}{d t}+\omega s \cdot p h_{s d 2} \\
V_{r d}=r r . i r d+\frac{d \mathrm{phrd}}{d t}-(\omega \mathrm{s}-\omega \mathrm{r}) \cdot \mathrm{ph} r q \\
V_{r q}=r r . i r q+\frac{d \mathrm{ph} r q}{d t}+(\omega \mathrm{s}-\omega \mathrm{r}) \cdot \mathrm{ph} r d
\end{array}\right.
$$

The electromagnetic torque is given by the following expression

$$
C e m=p \frac{L m}{L m+L r}(p h r d .(i s q 1+i s q 2)-p h r q .(i s d 1+i s d 2))
$$

\section{B. The principal of the field oriented control of the} DSIM

The complexity of the control of the asynchronous machines lies in the strong fort coupling exciting between the torque and the flux. Therefore, we proposes in this party, the control of speed by orientation of the flux, more precisely by orientation of the rotor flux, i.e, $\mathrm{phrd}=\mathrm{phr}$ and $\mathrm{phrq}=0[1]$. 
So, the block diagram of the control system considered is shown in (fig. 4).

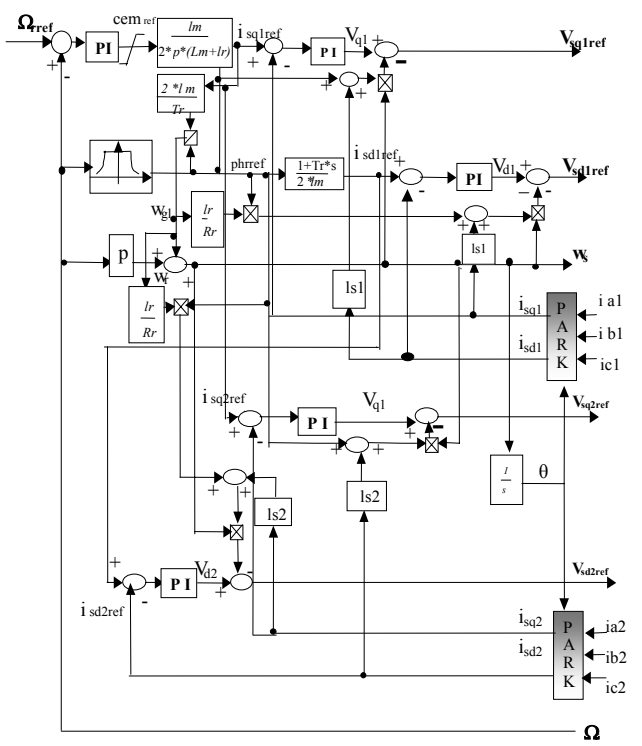

Fig. 4. The speed control using the algorithm $\mathrm{ph}_{\mathrm{rq}}=\mathbf{0}, \mathrm{ph}_{\mathrm{rd}}=\mathrm{ph}_{\mathrm{r}}$

\section{Speed control of the DSIM fed by two five levels NPC VSI}

In this part, they will study the performances of the speed control of the DSIM fed by two five levels NPC inverters controlled by the proposed strategy.
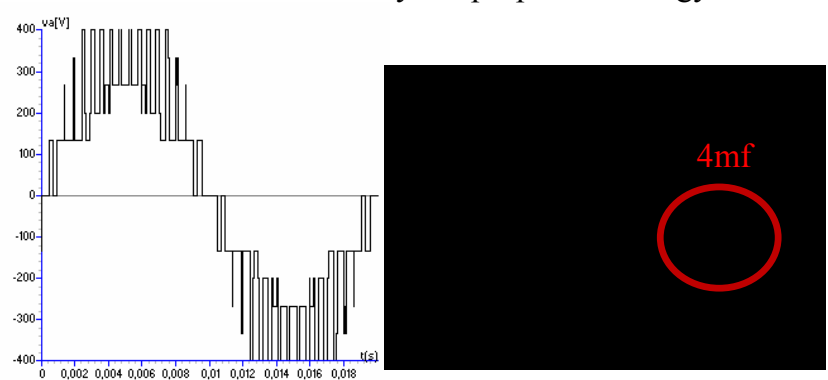

Fig. 5. The simple voltage of the inverter and its spectrum $(\mathrm{m}=12, \mathrm{r}=0.8)$

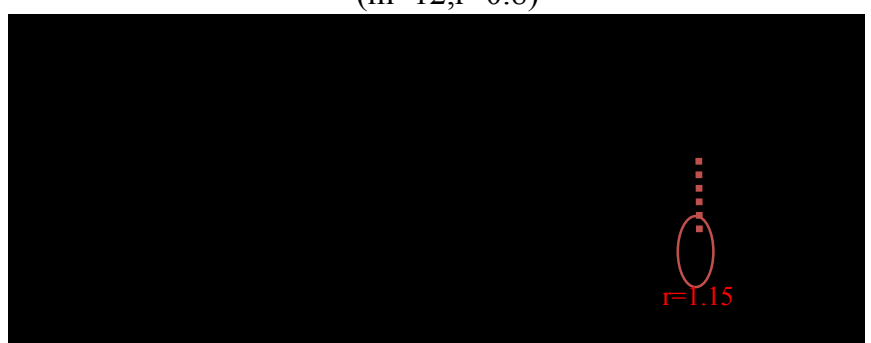

Fig. 6. The reglage characteristic of the output voltage of the inverter $(\mathrm{m}=12)$

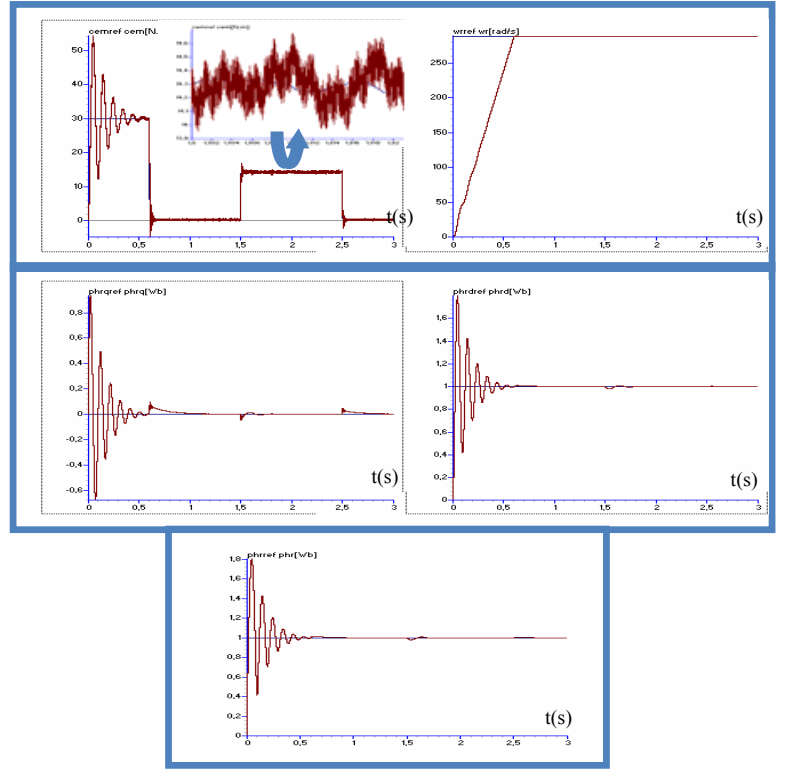

Fig. 7. Two five levels NPC inverters-DSIM cascade

A. Interpretation

- The output voltage present symmetry relatively to the quarter of the period. Then, only odd harmonious exist. These harmonious together by families centred around frequencies multiple of $4 \mathrm{mf}$.

- The reglage characteristic is linear from $r=0$ to $r_{\max }=1.15$.

- The harmonious rate decreases when $r$ increases.

- For the speed control algorithm of the DSIM, the results obtained show:

*The direct flux $\mathrm{ph}_{\mathrm{rd}}$ is practically null.

*The speed follows quickly its reference.

\section{Two batteries- two capacitors filters- two five NPC VSI-DSIM cascade}

The authors study a stability problem of the input DC voltages. For that, they study a cascade presented in (fig. 8). 


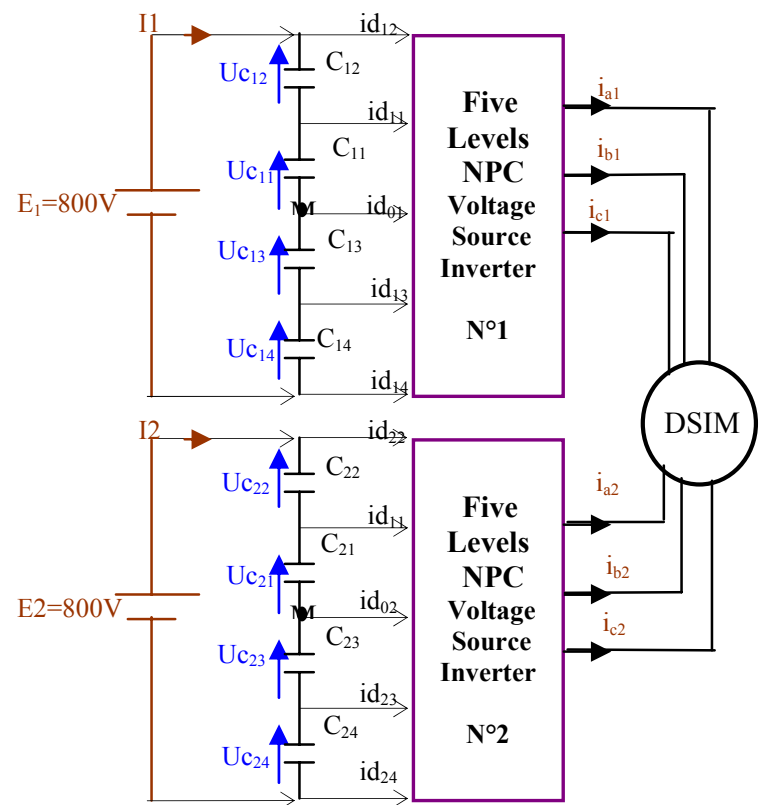

Fig. 8. Two batteries-two capacitors filters-two five levels NPC VSI-DSIM cascade

A. Modelling of the intermediate capacitor filter

The two capacitors filters are identical. The model of this filter is defined as follow, with $\mathrm{J}=1,2$ : [1]

$$
\left\{\begin{array}{c}
C_{J 1} \frac{d U_{c J 1}}{d t}=I_{J}-i d_{J 2}-i d_{J 1} \\
C_{J_{2} 2} \frac{d U_{c J} 2}{d t}=I_{J}-i d_{J 2} \\
C_{J 3} \frac{d U_{c J 3}}{d t}=I_{J}+i d_{J 3}+i d_{J 4} \\
C_{J 4} \frac{d U_{c J} 4}{d t}=I_{J}+i d_{J 4}
\end{array}\right.
$$

\section{B. Simulation results}

The parameters of the two intermediates capacitors filters are defined with $C_{\mathrm{Ji}}(\mathrm{J}=1,2 \mathrm{i}=1 \div 4)=\mathrm{C}=20 \mathrm{mf}$, the two batteries voltages are fixed at $\mathrm{E} 1=\mathrm{E} 2=800 \mathrm{~V}$.

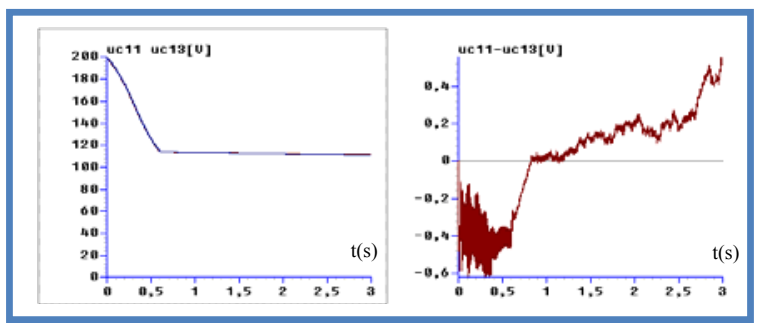

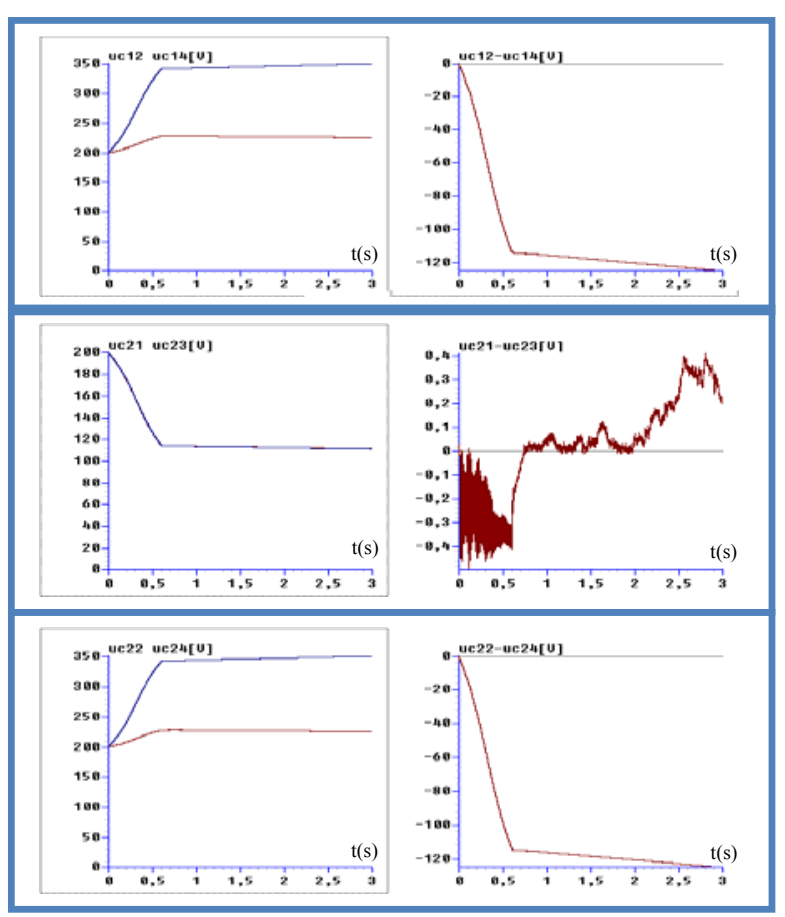

Fig. 9. The two intermediates filters voltages and hers differences

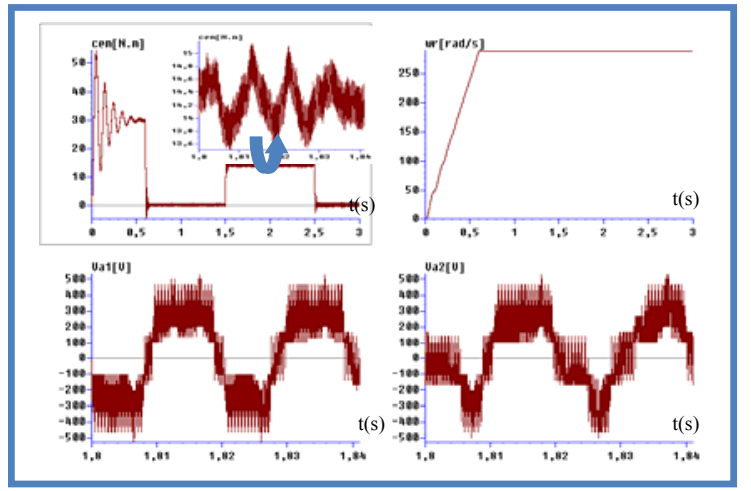

Fig. 10. Two five levels NPC inverter-DSIM cascade

\section{Interpretation}

The authors show in (Fig. 9), the unbalance of the different input DC voltages sources of the two five levels NPC VSI. This fact accentuates the problem of the instability of the output voltages (fig. 10). To remedy to this problem for to equalise the different DC voltages, they introduce in the cascade a clamping bridge.

\section{The Clamping Bridge}

It is constituted by a transistor and resistor in the capacitor borne [1] (Fig. 11). The transistors are controlled in order to maintain an equality of the different voltages. 


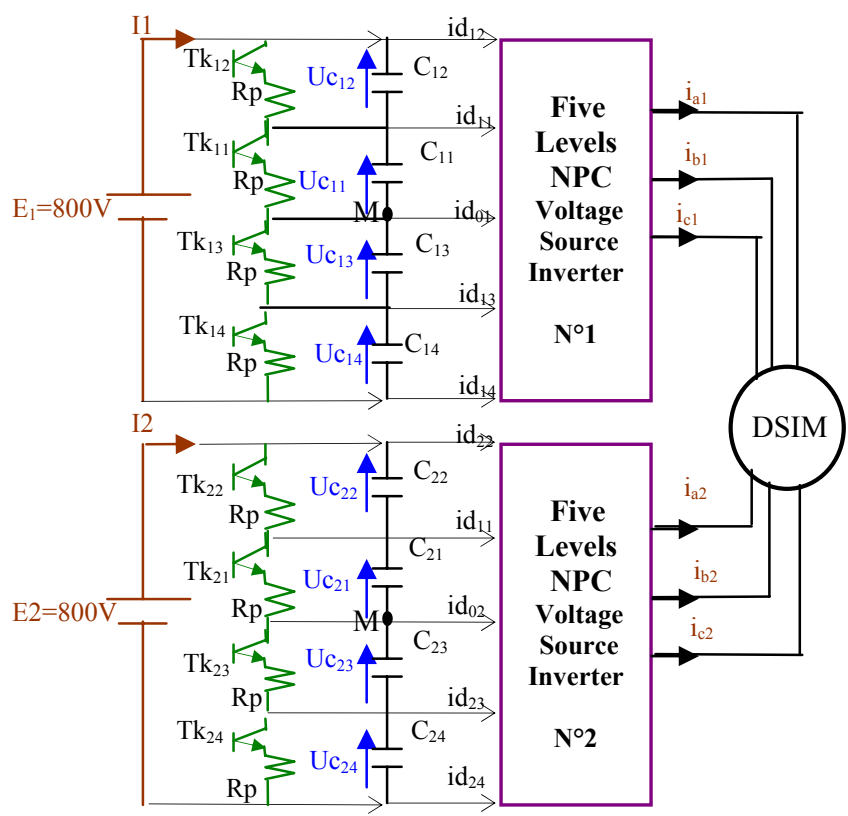

Fig. 11. Two batteries-two clamping bridges-two capacitors filters-two five levels NPC VSI-DSIM cascade.

\section{A. Simulation results}

The parameters of the two intermediates capacitors filters and the clamping bridge are defined: $\mathrm{i}=1 \div 4)=20 \mathrm{mF}$ and $\mathrm{Rp}=25 \Omega$. The two batteries voltages are fixed at $\mathrm{E} 1=\mathrm{E} 2=800 \mathrm{~V}$

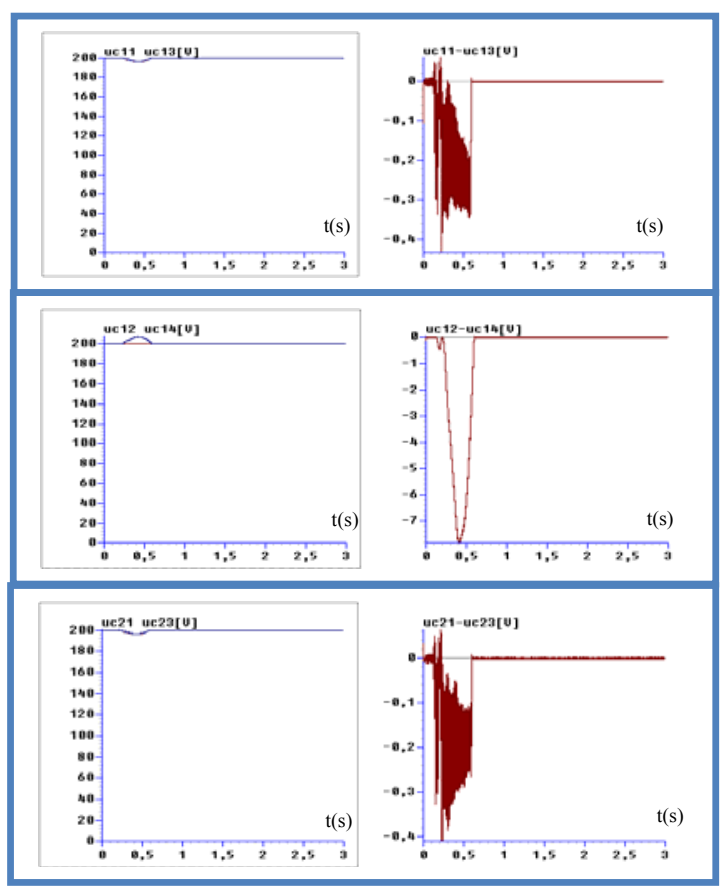

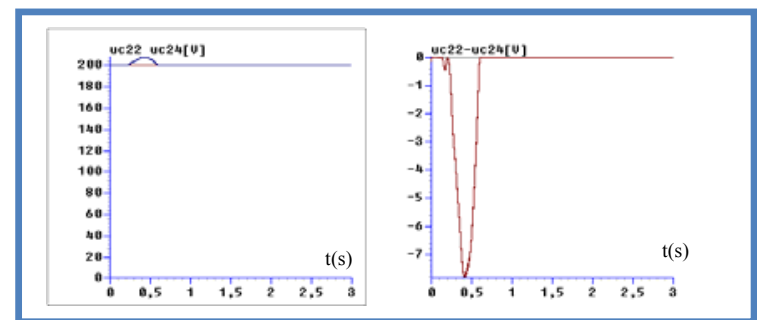

Fig. 12. The clamping bridge voltages and their differences

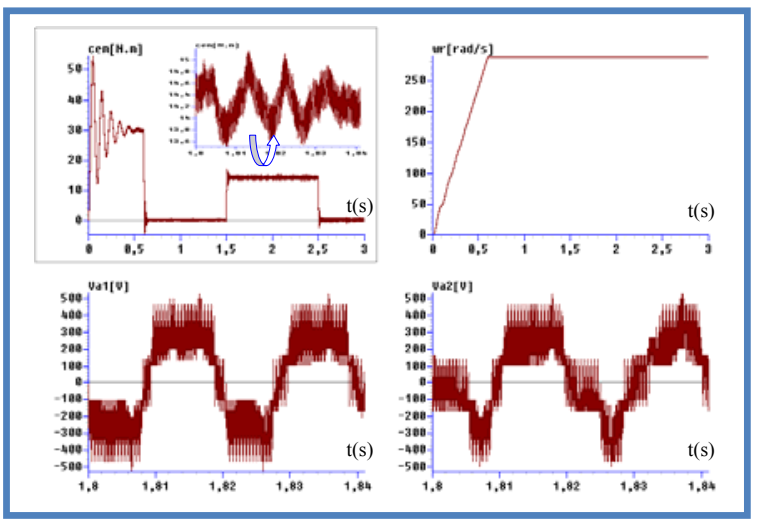

Fig. 13. Two five levels NPC inverters-DSIM cascade.

\section{A. Interpretation}

-The (fig. 12 and 13) show the simulation results with a clamping bridge. The authors note that the DC voltages of two five levels NPC VSI are equals by pairs $\left(\mathrm{U}_{\mathrm{cJ} 1}=\mathrm{U}_{\mathrm{cJ} 3}, \mathrm{U}_{\mathrm{cJ} 2}=\mathrm{U}_{\mathrm{cJ} 4}\right)$, so constant after a transient state. They observed too, that the here difference $\left(\mathrm{U}_{\mathrm{cJ} 1}-\mathrm{U}_{\mathrm{cJ} 3}, \mathrm{U}_{\mathrm{cJ} 2}-\mathrm{U}_{\mathrm{cJ} 4}\right)$ is decrease to have a value practically null in steady states (fig. 12).

-The (fig. 13) shows that the system is not very sensitive to the variation of the couple of load of the machine.

\section{Conclusion}

In this paper, they have studied stability problem of the input DC voltages sources inverter, for that, they study the cascade constituted by two batteries-two capacitors filters- two five levels NPC VSI-DSIM. First they have proposed a space vector modulation strategy with four bipolar carries to control the inverter. The results of this strategy show a clear improvement for the harmonics row and get widen the adjustment linear area without modifying the performances of the speed control of a DSIM fed by this inverters. Then, they study the cascade, the authors note the instability of the input voltages, i.e, that the upper input DC voltages of the inverter $\left(\mathrm{U}_{\mathrm{cJ} 1}, \mathrm{U}_{\mathrm{cJ} 2}\right)$ are practically not equals to the lower one 
$\left(\mathrm{U}_{\mathrm{cJ} 3}, \mathrm{U}_{\mathrm{cJ} 4}\right)$. This fact accentuates the problem of unbalance of the different input DC voltages sources of the two five levels NPC VSI, so instability of the output voltages. To remedy to this problem, they propose to use clamping bridge. Its introduction in the cascade leads to balance all the DC voltages sources of the two five levels NPC VSI. The results obtained with this solution are full of promise to be used to stabilise the input DC voltages of the inverter, so promise to use the inverter in high voltage and great power applications.

\section{Acknowledgement}

wr, ws and wgl: rotor, stator angular frequency and slip frequency

Cem: electromagnetic torque;

Qr: angular speed of the rotor;

Phrd, phrq : direct, quadrate rotor flux;

phr : resultant rotor flux;

phsd1,phsd2,phsq1,phsq2 : stators flux in the dq reference frame;

Is1,Is2,Ir: inductance of stator leakage of the two windings and of the rotor;

Lm: mutual inductance;

rs1,rs2,rr : resistances of the two stator windings and of the rotor;

$\mathbf{S}=\mathbf{d} / \mathbf{d t}$ : differential operator;

isd1,isd2, isq1, isq2: stators currents in the dq reference frame;

ird,irq: rotor current in the dq reference frame.

vsd1,vsd2, vsq1, vsq2: d-axis and q-axis stators voltages.

\section{REFERENCES}

[1]S. Arezki: « Contribution to the study and the ordering of an asynchronous machine double star supplied with multilevel inverters». Magister thesis, Houari Boumediene University, Bab Ezzouar, Algeria, 2005.

[2] S. Arezki, E.M. Berkouk: «Modelling and Control of an Asynchronous Machine Double Star (DSIM) fed by Two Inverters on Five Levels with Structure NPC». National Conference on the Electric Genius, CNGE' 04- Tiaret, Algerie.

[3] Z. Oudjebour, E.M. Berkouk, N. Sami, S. Belgasmi, S. Arezki, I. Messaif: « Indirect space vector control of a double star induction machine fed by two five- levels NPC VSI ». International Conference on Electric Machine, ICEM'04, Pologne

[4] Z. CHEN, AC. WILLIAMSON: « Simulation study of a double three phase electric machine ». International Conference on Electric Machine, ICEM'98, 1998, vol.1, pp215-220. 